\title{
Time-enhanced performance of oxide thermoelectric modules based on a hybrid $p-n$
} junction

Kanas, Nikola; Bjørk, Rasmus; Wells, Kristin Høydalsvik; Schuler, Raphael; Einarsrud, Mari Ann; Pryds, Nini; Wiik, Kjell

\section{Published in:}

ACS Omega

Link to article, DOI:

10.1021/acsomega.0c04134

Publication date:

2021

Document Version

Publisher's PDF, also known as Version of record

Link back to DTU Orbit

Citation (APA):

Kanas, N., Bjørk, R., Wells, K. H., Schuler, R., Einarsrud, M. A., Pryds, N., \& Wiik, K. (2021). Time-enhanced performance of oxide thermoelectric modules based on a hybrid p-n junction. ACS Omega, 6(1), $197-205$. https://doi.org/10.1021/acsomega.0c04134

\section{General rights}

Copyright and moral rights for the publications made accessible in the public portal are retained by the authors and/or other copyright owners and it is a condition of accessing publications that users recognise and abide by the legal requirements associated with these rights.

- Users may download and print one copy of any publication from the public portal for the purpose of private study or research.

- You may not further distribute the material or use it for any profit-making activity or commercial gain

- You may freely distribute the URL identifying the publication in the public portal 


\section{Time-Enhanced Performance of Oxide Thermoelectric Modules Based on a Hybrid $\mathrm{p}-\mathrm{n}$ Junction}

Nikola Kanas,* Rasmus Bjørk, Kristin Høydalsvik Wells, Raphael Schuler, Mari-Ann Einarsrud, Nini Pryds, and Kjell Wiik

Cite This: ACS Omega 2021, 6, 197-205

Read Online

\section{ACCESS |}

Џlll Metrics \& More

Article Recommendations

Supporting Information

ABSTRACT: The present challenge with all-oxide thermoelectric modules is their poor durability at high temperatures caused by the instability of the metal-oxide interfaces at the hot side. This work explains a new module concept based on a hybrid $\mathrm{p}-\mathrm{n}$ junction, fabricated in one step by spark plasma co-sintering of $\mathrm{Ca}_{3} \mathrm{Co}_{4-x} \mathrm{O}_{9+\delta}$ (CCO, p-type) and $\mathrm{CaMnO}_{3-\delta} / \mathrm{CaMn}_{2} \mathrm{O}_{4}$ (CMO, n-type). Different module (unicouple) designs were studied to obtain a thorough understanding of the role of the in situ formed hybrid $\mathrm{p}-\mathrm{n}$ junction of $\mathrm{Ca}_{3} \mathrm{CoMnO}_{6}(\mathrm{CCMO}, \mathrm{p}$-type) and Co-oxide rich phases ( $\mathrm{p}$ type) at the $\mathrm{p}-\mathrm{n}$ junction $\left(>700{ }^{\circ} \mathrm{C}\right)$ in the module performance. $\mathrm{A}$ time-enhanced performance of the modules attributed to this $\mathrm{p}-\mathrm{n}$ junction formation was observed due to the unique electrical properties of the hybrid $\mathrm{p}-\mathrm{n}$ junction being sufficiently conductive

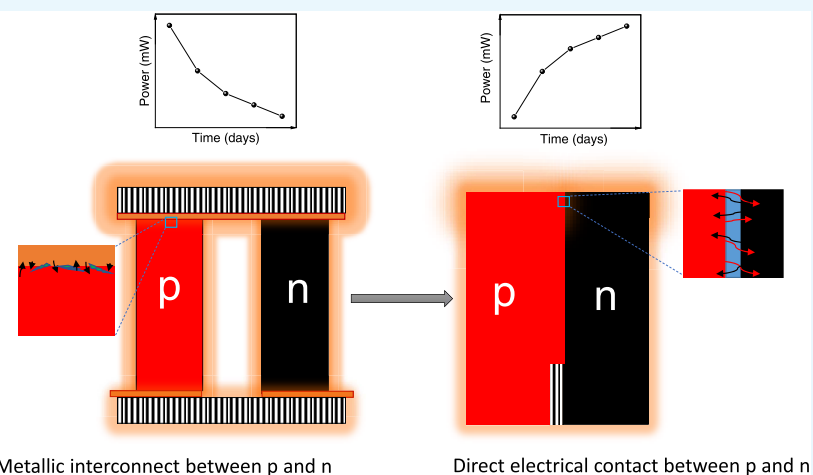
at high temperatures $\left(>700{ }^{\circ} \mathrm{C}\right)$ and nonconductive at moderate and low temperatures. The alteration of module design resulted in a variation of the power density from $12.4(3.1)$ to $28.9 \mathrm{~mW} / \mathrm{cm}^{2}(7.2 \mathrm{~mW})$ at $\Delta T \sim 650{ }^{\circ} \mathrm{C}$ after 2 days of isothermal hold $\left(900{ }^{\circ} \mathrm{C}\right.$ hot side). This new concept provides a facile method for the fabrication of easily processable, cheap, and high-performance hightemperature modules.

\section{INTRODUCTION}

Waste heat released during high-temperature processes (e.g., in the metallurgical industry) is significant with respect to costand energy-effective production. ${ }^{1}$ Thermoelectric generators (TEGs) convert heat directly into electrical energy, thus representing promising technology for waste heat harvesting. The materials which constitute these devices are often toxic and expensive metals and alloys, ${ }^{2,3}$ and their use is also hampered by severe limitations due to oxidation and low melting temperatures. This paves the way for oxide-based TEGs, which provide chemical and thermal stability at high temperatures, and in addition are low-cost and environmentally friendly. ${ }^{4}$ To date, the electrical output power of oxide-based TEGs is generally lower than that of the state-ofthe-art TEGs. ${ }^{5}$ However, the output power is not always the key parameter to evaluate TE modules. For instance, TE modules, which generate a moderate electric power and possess good durability, are recognized as potential power sources for wireless sensors that could continuously operate at elevated temperatures. ${ }^{6}$

Currently, the main strategies to improve the efficiency of oxide-based TE modules for waste heat harvesting are improving the doping of the individual $\mathrm{p}$ - and $\mathrm{n}$-type materials to enhance their performance, ${ }^{7}$ reducing the contact resistance, ${ }^{8,9}$ and including barrier layers to reduce diffusion. ${ }^{10}$
A notable improvement was achieved with "leg-segmented modules"; ${ }^{11-13}$ however, oxide-based modules still suffer from poor durability caused by the instability of the metal-oxide interfaces at the hot side. ${ }^{14}$ Hence, there is a demand for new approaches and strategies to improve the performance of oxide-based modules in terms of long operation time under a high-temperature gradient.

$\mathrm{Ca}_{3} \mathrm{Co}_{4-x} \mathrm{O}_{9+\delta}(\mathrm{CCO})$ is one of the most promising oxide thermoelectric p-type materials for high-temperature applications. ${ }^{15-17}$ It has a misfit-layered structure consisting of two sublattices: a rock salt $\mathrm{Ca}_{2} \mathrm{CoO}_{3}$ and a $\mathrm{CdI}_{2}$-type $\mathrm{CoO}_{2}{ }^{15,16}$ The two sublattices have different $b$ parameters, which results in an incommensurable crystal structure. The application of $\mathrm{CCO}$ in air is limited to temperatures below $930{ }^{\circ} \mathrm{C}$ due to decomposition. ${ }^{17}$

$\mathrm{CaMnO}_{3-\delta}$ is a promising thermoelectric n-type material with a perovskite structure. ${ }^{18}$ At $900{ }^{\circ} \mathrm{C}$ in air, the cubic phase is stable, changing to tetragonal and orthorhombic phases with

Received: August 26, 2020

Accepted: December 8, 2020

Published: December 28, 2020 
decreasing temperature. ${ }^{19}$ It has recently been shown that $\mathrm{CaMnO}_{3-\delta}$-based composites ( $\mathrm{CMO}$ ), composed of $\mathrm{CaMnO}_{3-\delta}$ as the major phase and $\mathrm{CaMn}_{2} \mathrm{O}_{4}$ as the minor phase, demonstrated better TE performance than pristine $\mathrm{CaMnO}_{3-\delta}$ due to enhanced electrical conductivity. ${ }^{20}$ Hence, this material is selected as the n-type material in this work.

At high temperatures, $\mathrm{CCO}$ and $\mathrm{CMO}$ react to form $\mathrm{Ca}_{3} \mathrm{CoMnO}_{6}$ (CCMO). CCMO crystallizes in the $\mathrm{A}_{3} \mathrm{BB}^{\prime} \mathrm{O}_{6}$ structure, consisting of alternating face-sharing $\mathrm{CoO}_{6}$ octahe$\mathrm{dra}$ and trigonal biprismic chains, with $\mathrm{Ca}$ ions between the chains. ${ }^{21,22}$ Electrical conductivity increases exponentially above $800{ }^{\circ} \mathrm{C}$ due to the pronounced polaron hopping mechanism, reaching a maximum of $10^{-4} \mathrm{~S} \cdot \mathrm{cm}^{-1}$ at $900{ }^{\circ} \mathrm{C}$, followed by a high positive Seebeck coefficient. ${ }^{23}$ Hightemperature stability of $\mathrm{Ca}_{3} \mathrm{Co}_{2-x} \mathrm{Mn}_{x} \mathrm{O}_{6}$ for $1<x<0.75$ has been reported. ${ }^{24}$

In our recent publication, a prototype TE module consisting of p-type $\mathrm{CCO}$ and n-type $\mathrm{CMO}$ with a $\mathrm{p}-\mathrm{p}-\mathrm{n}$ junction ( $\mathrm{CCO} / \mathrm{CCMO} / \mathrm{CMO}$ ) demonstrated promising performance $\left(\sim 23 \mathrm{~mW} / \mathrm{cm}^{2}\right)$ attributed to the formation of the nonrectifying $\mathrm{p}-\mathrm{p}-\mathrm{n}$ junction and unexpectedly high open-circuit voltage. In this work, parts of the legs were separated by $\mathrm{LaAlO}_{3}$ (LAO), which is an electrical insulator, while direct contact between $\mathrm{CMO}$ and $\mathrm{CCO}$ was established at the hightemperature end. ${ }^{25}$ The origin of the enhanced performance is only partially understood and was attributed to CCMO formation at the $\mathrm{p}-\mathrm{n}$ junction on the hot side of the module. Later, a detailed transmission electron microscopy (TEM) study of the $\mathrm{CCO}-\mathrm{CMO}$ interface showed that both the $\mathrm{CCMO}$ and Co-oxide phases formed at $900{ }^{\circ} \mathrm{C}$, and the interdiffusion and phase distribution were more accurately described. ${ }^{26}$ However, the understanding of how the module design, including the hybrid $\mathrm{p}-\mathrm{n}$ junction, affects the performance is lacking.

In the present study, we use the novel concept of a hybrid $\mathrm{p}-\mathrm{n}$ junction and analyze the performances of modules with various different designs to elaborate on the impact of the formation of the reaction layers. Our hypothesis based on previous work is that the formation of CCMO and Co-oxide will establish sufficient electrical contact and conductivity at high temperatures (hybrid $\mathrm{p}-\mathrm{n}$ junction), and act as an electrical insulator at medium and low temperatures due to the low electrical conductivities of both the phases. A comprehensive understanding of the time-enhanced performance of oxide modules based on the hybrid $\mathrm{p}-\mathrm{n}$ junction is provided in addition to a discussion on future module design.

\section{RESULTS}

Figure 1 shows a schematic illustration of the four different modules investigated. The aim of different designs was to obtain a more thorough understanding of the role of the hybrid $\mathrm{p}-\mathrm{n}$ junction with respect to the module performance.

Figure 2a shows the thermoelectric performance of Module1-0h with 700,800 , and $900{ }^{\circ} \mathrm{C}$ hot side temperatures, corresponding to $\Delta T$ of 512,606 , and $652{ }^{\circ} \mathrm{C}$, respectively. The properties, $V_{\mathrm{oo}} I_{\mathrm{sc}}$ and $P_{\max }$ of Module1-0h are enhanced with increasing hot side temperature, reaching maximum values of $207 \mathrm{mV}, 50 \mathrm{~mA}$, and $2.7 \mathrm{~mW}$ at $900{ }^{\circ} \mathrm{C}(\Delta T=652$ ${ }^{\circ} \mathrm{C}$ ), respectively. Performance of Module1-0h, as a function of time at the maximum hot side temperature $\left(900{ }^{\circ} \mathrm{C}\right)$ is shown in Figure 2b. Time-enhanced performance of the Module1-0h is observed corresponding to 11,14 , and $14.5 \%$ increase in $V_{\text {oo }}$ $I_{\text {so }}$ and $P_{\text {max }}$ respectively.

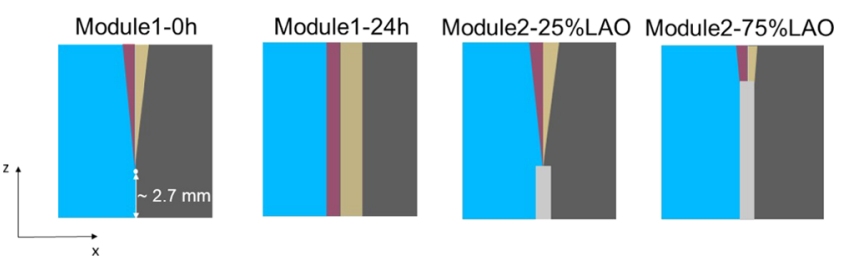

Figure 1. Two-dimensional (2D) schematic illustrations of the designs $(z \sim 10.7 \mathrm{~mm})$ of the modules investigated. Blue, bright gray, and black parts represent n-type (CMO), insulator (LAO), and p-type (CCO) materials, with thicknesses of $x(\mathrm{CCO}) \sim 0.9, x(\mathrm{CMO}) \sim$ 3.5 , and $x(\mathrm{LAO}) \sim 0.3 \mathrm{~mm}$, respectively. Module 1-24h showed the uniform thickness of CCMO and Co-oxide-based interfacial layers (reddish and brownish) due to isothermal annealing at $900{ }^{\circ} \mathrm{C}$ prior to testing. CCMO and Co-oxide-based layers in Module1-0h, Module2-25\%LAO, and Module2-75\%LAO were formed as a result of reactions between $\mathrm{CCO}$ and $\mathrm{CMO}$ during testing while $\Delta T$ was applied.

Although both $V_{\text {oc }}$ and $P_{\max }$ show a continuous enhancement with time, $I_{\mathrm{sc}}$ increases stepwise, which could be due to the improved electrical contact between the active components within the hybrid junction during testing at high temperatures. The performance of Module1-24h is presented in Figure 2c, and shows higher values of $V_{\mathrm{oc}}, I_{\mathrm{sc}}$ and $P_{\max }$ compared with Module1-0h, reaching a maximum power output of about 4.4 $\mathrm{mW}$ at $900{ }^{\circ} \mathrm{C}$. Furthermore, during isothermal testing at 900 ${ }^{\circ} \mathrm{C}$, all three parameters increase (Figure $2 \mathrm{~d}$ ).

Figure 3a shows the performance of Module2-25\%LAO where LAO is located at the cold side, separating the active components. Separation of $25 \%$ of the height was done to prevent short-circuiting in the $\mathrm{p}-\mathrm{n}$ junction area at the cold side, which does not react at $\Delta T=650{ }^{\circ} \mathrm{C}\left(900{ }^{\circ} \mathrm{C}\right.$ hot side $)$ to form the hybrid $\mathrm{p}-\mathrm{n}$ junction (more details in Figure 5). A $P_{\max }$ of about $3.5 \mathrm{~mW}$ and $V_{\mathrm{oc}}$ of about $205 \mathrm{mV}$ were obtained at $900{ }^{\circ} \mathrm{C}$ hot side $\left(\Delta T \sim 652{ }^{\circ} \mathrm{C}\right)$. Module2-25\%LAO showed a lower $P_{\max }$ than Module1-24h, but higher than Module1-0h, which is a result of variation in $I_{\mathrm{sc}}$.

Time-enhanced performance, similar to that of Module1-0h, was also observed during the isothermal hold at $900{ }^{\circ} \mathrm{C}$ (Figure 3b), corresponding to about 21, 4, and $14 \%$ enhancement in $P_{\max }, V_{\text {oc }}$ and $I_{\text {sc }}$ respectively.

Figure $3 c$ shows the performance of Module2-75\%LAO with $75 \%$ separation of the active components by LAO, and represents the best performance of the modules investigated, corresponding to $P_{\max }$ and $V_{\mathrm{oc}}$ of $7 \mathrm{~mW}$ and $350 \mathrm{mV}$, respectively, at $900{ }^{\circ} \mathrm{C}$ (hot side). The performance is better than those of modules reported with undoped $\mathrm{CCO}$ and $\mathrm{CMO},{ }^{27,28}$ and comparable to modules consisting of Bi-doped $\mathrm{CCO}$ and Mo-doped CMO. ${ }^{29}$

During the isothermal hold at $900{ }^{\circ} \mathrm{C}$ (Figure 3d), the timeenhanced $P_{\max }$ resulted in an increase of about $4 \%$, in spite of a gradual reduction in $V_{\mathrm{oc}} . I_{\mathrm{sc}}$ increased stepwise, resulting in a total increase of about $7 \%$. Numerical values for the thermoelectric performance of all of the modules as well as $\%$ change during isothermal hold are summarized in Table 1.

Figure 4 presents the calculated $V_{\text {oc }}$ according to COMSOL modeling, as a function of cold side temperature and the extent of $\mathrm{p}-\mathrm{n}$ separation corresponding to Module1-0h, Module225\%LAO, and Module2-75\%LAO. The modeling (2D) is based on the geometries shown in Figure 1, without considering the properties of phases formed (CCMO and Co-oxide) during the test. The hot side temperature was kept constant at $900{ }^{\circ} \mathrm{C}$. The calculations were based on the 

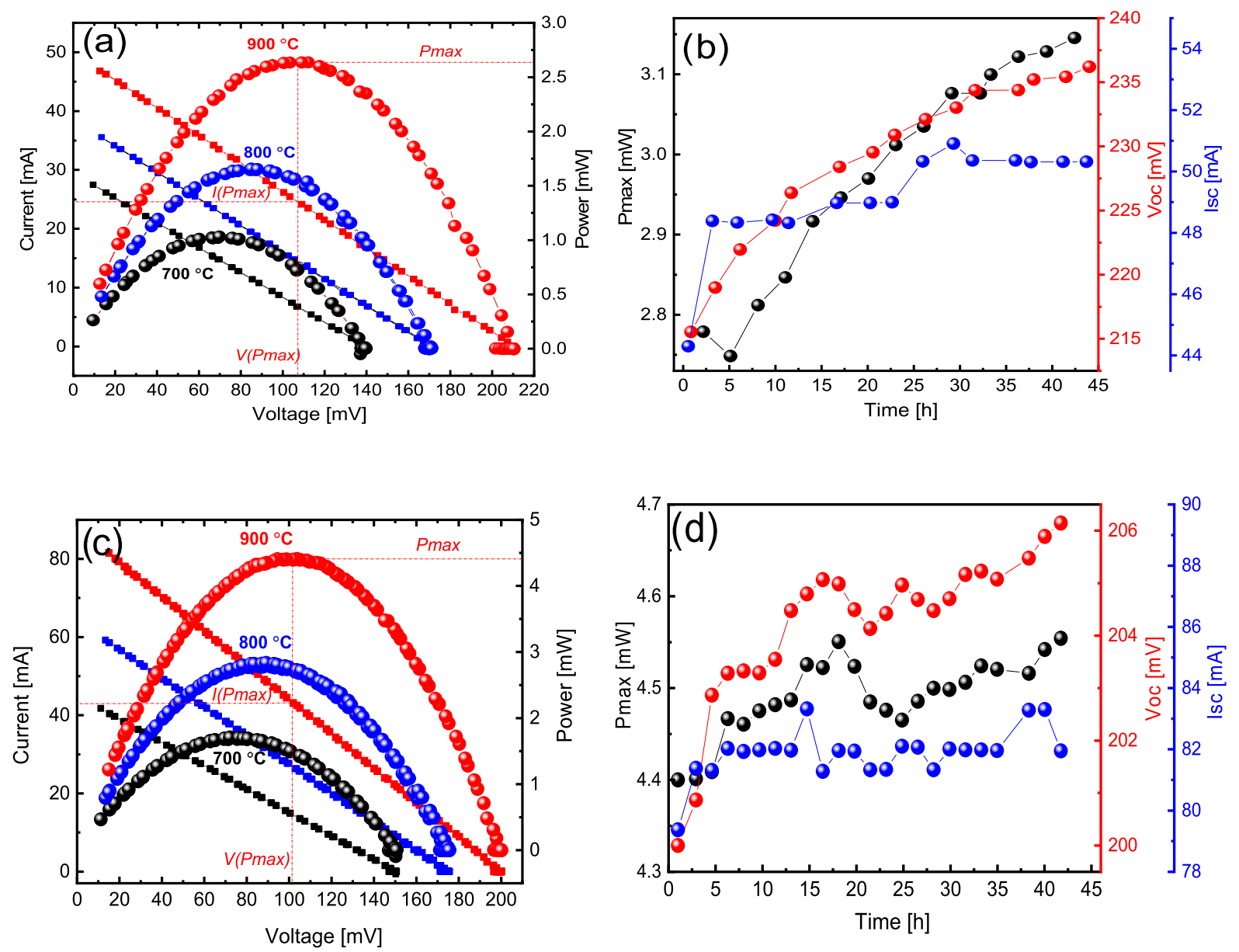

Figure 2. Thermoelectric performance of (a) Module1-0h and (c) Module1-24h. Open-circuit voltage $\left(V_{\text {oc }}\right)$, short-circuit current $\left(I_{\text {sc }}\right)$, and maximum electrical power output $\left(P_{\max }\right)$ as a function of dwelling time at $900{ }^{\circ} \mathrm{C}$ on the hot side of the respective modules are shown in $(\mathrm{b})$ and (d). Black, blue, and red data points in (a) and (c) correspond to 700,800 , and $900{ }^{\circ} \mathrm{C}$ hot side temperatures, respectively, with the corresponding $\Delta T$ of 512,606 , and $652{ }^{\circ} \mathrm{C}$.

Seebeck coefficients for CCO and CMO materials reported by Kanas et al., ${ }^{25}$ and as expected, $V_{\text {oc }}$ increases with $\Delta T$. The experimental values obtained for $V_{\text {oc }}$ (Table 1) are included in Figure 4 (diamonds) and are significantly higher than $V_{\mathrm{oc}}$ resulting from COMSOL modeling. It is interesting to note that the difference between calculated and measured opencircuit voltages $\left(\Delta V_{\text {oc }}\right)$ decreases with increasing degree of separation between the $\mathrm{n}$ - and p-type materials. The highest $V_{\text {oc }}$ modeled are for a module where the $\mathrm{p}$ - and n-legs are separated and connected by a metallic interconnect at the hightemperature side of the module, i.e., a conventional device, which is not realized experimentally in the present work. To obtain full matching of experimental and theoretical data in the whole range of separations, the modeling should also include the contribution from the hybrid $\mathrm{p}-\mathrm{n}$ junction.

After the assessment of the performance of Module1-0h, the microstructure was analyzed by scanning electron microscopy (SEM) on cross-sections at the hot and cold side of the module (Figure 5). Microstructures in the vicinity of the $\mathrm{p}-\mathrm{n}$ interface exposed to $\sim 250{ }^{\circ} \mathrm{C}$ (Figure $5 \mathrm{~d}-\mathrm{f}$ ) were significantly different from those exposed to $\sim 900{ }^{\circ} \mathrm{C}$ (Figure 5a-c). Pronounced grain growth and increase in pore size were observed at the hot side of the module, along with the formation of CCMO and Co-oxide enriched layers at and in the vicinity of the interface, which is in accordance with our previous study. ${ }^{25}$ Both in situ formed layers are much denser than the surrounding matrix, and the "gap" along the $\mathrm{p}-\mathrm{n}$ junction is due to the material being pulled out during polishing. The transition point from unreacted (Figure 5e) to reacted $\mathrm{p}-\mathrm{n}$ junction (Figure $5 \mathrm{~b}$ ) was determined by SEM to be about $25 \%$ of the total height (bottom up). This is also illustrated in Figure 1 (Module1-0h).

The microstructural changes in the $\mathrm{p}$ - and n-type materials along the entire height are the same in all modules, due to the same geometry of the modules and the same thermal gradient applied. Hence, there are no significant differences in the material properties among the modules, and hence the observed $V_{\text {oc }}$ discrepancy is attributed to the different areas left for the formation of the hybrid $\mathrm{p}-\mathrm{n}$ junction.

The reactions between $\mathrm{CCO}$ and $\mathrm{CMO}$ were studied separately, and Figure 6a,b shows the time dependency of the thicknesses of the in situ formed CCMO and Co-oxide layers as a function of isothermal heat treatment $(1,3,6,12,24$, and $48 \mathrm{~h}$ ) at 900 and $700{ }^{\circ} \mathrm{C}$, respectively. At both temperatures, the thicknesses of the Co-oxide layers are significantly larger than those of CCMO. The Co-oxide layer achieves a thickness of about $20 \mu \mathrm{m}$ after $50 \mathrm{~h}$ dwell time at both 700 and $900{ }^{\circ} \mathrm{C}$, whereas CCMO layers were of 0.5 and $2 \mu \mathrm{m}$, respectively. The influence of the formed layers on the electrical properties was further investigated, and the resistance $\left(\Omega \cdot \mathrm{cm}^{-2}\right)$ across the assintered $\mathrm{CMO}-\mathrm{CCO}$ pellets was continuously monitored for $70 \mathrm{~h}$ at 700,800 , and $900{ }^{\circ} \mathrm{C}$ (Figure $6 \mathrm{c}$ ). There is a significant 

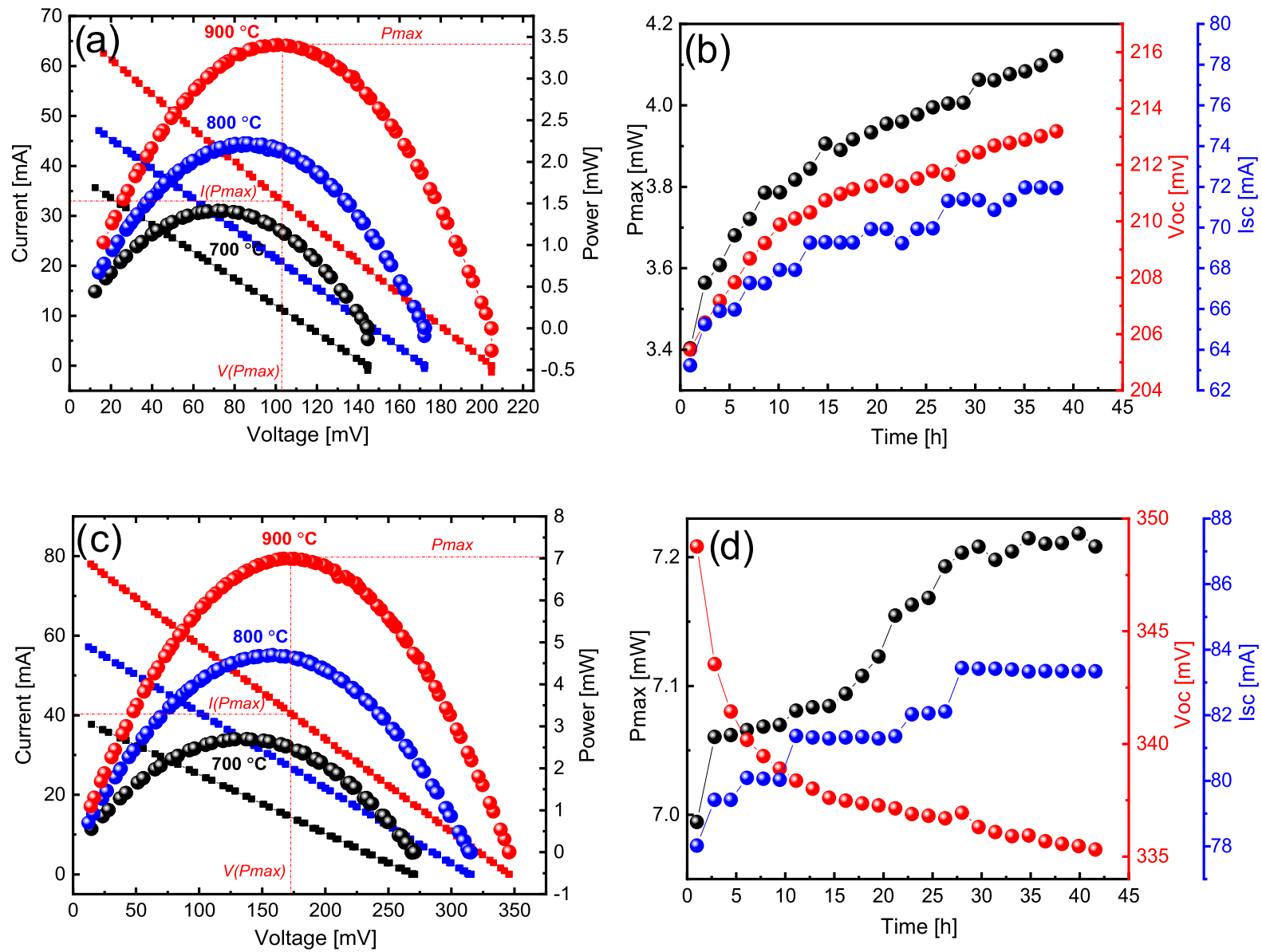

Figure 3. Thermoelectric performance of (a) Module2-25\%LAO and (c) Module2-75\%LAO. Black, blue, and red data points in (a) and (c) are related to 700,800 , and $900{ }^{\circ} \mathrm{C}$ hot side temperatures, respectively, with the corresponding $\Delta T$ of 512,606 , and $652{ }^{\circ} \mathrm{C}$. Open-circuit voltage $\left(V_{\text {oc }}\right)$, short-circuit current $\left(I_{\text {sc }}\right)$, and electrical power output $\left(P_{\max }\right)$ as a function of dwelling time at $900{ }^{\circ} \mathrm{C}$ hot side of $(\mathrm{b})$ Module2-25\%LAO and (d) Module2-75\%LAO.

Table 1. Overview of Properties of the TE Modules of Different Designs Prior to the Isothermal Dwelling ${ }^{a a}$

\begin{tabular}{|c|c|c|c|c|c|}
\hline & $P_{\max }[\mathrm{mW}]$ & $V_{\mathrm{oc}}[\mathrm{mV}]$ & $I_{\mathrm{sc}}[\mathrm{mA}]$ & $V\left(P_{\max }\right)[\mathrm{mV}]$ & $I\left(P_{\max }\right)[\mathrm{mA}]$ \\
\hline Module1-0h & $2.7(14.5 \%)$ & $205(11 \%)$ & $50(14 \%)$ & 108 & 25 \\
\hline Module1-24h & $4.4(3 \%)$ & $200(3 \%)$ & $84(2.6 \%)$ & 101 & 42.5 \\
\hline Module2-25\%LAO & $3.5(21 \%)$ & $206(4 \%)$ & $68(14 \%)$ & 102 & 33 \\
\hline Module2-75\%LAO & $7.0(4 \%)$ & $350(-3 \%)$ & $80(7 \%)$ & 174 & 40 \\
\hline
\end{tabular}

${ }^{a}$ Values in brackets represent a time-dependent increase or decrease (marked with negative sign) in module properties at $900{ }^{\circ} \mathrm{C}$ hot side and 250 ${ }^{\circ} \mathrm{C}$ cold side after $\sim 48 \mathrm{~h}$.

decrease in resistance with increasing temperature and the resistance at 700 and $800{ }^{\circ} \mathrm{C}$ shows a moderate decrease with time, and the opposite trend is observed at $900{ }^{\circ} \mathrm{C}$. This is probably related to the increasing thickness of the dense CCMO layer at $900{ }^{\circ} \mathrm{C}$ (Figure 6a) since the Co-oxide layer is formed as separate grains (not a continuous barrier) and as such does not affect the resistance that much. However, the main voltage drop occurs over the junction, and the resistivity of active components does not contribute. The resistance contribution of $\mathrm{CCO}$ and $\mathrm{CMO}$ at 700,800 , and $900{ }^{\circ} \mathrm{C}$ is given in Table $\mathrm{S} 1$ and compared to the resistance of the junction (Supporting Data).

High-temperature X-ray diffraction (HT-XRD) patterns of homogeneously mixed $\mathrm{CCO}-\mathrm{CMO}$ powders are presented in Figure 7. The presence of both $\mathrm{CMO}$ and $\mathrm{CCO}$ is evident at room temperature, and the intensity of the $\mathrm{CCO}$ diffraction peaks increases with temperature due to increasing crystal- linity. At $714{ }^{\circ} \mathrm{C}$, the diffraction lines of $\mathrm{CCMO}$ and $\mathrm{Co}_{3} \mathrm{O}_{4}$ appear, and the intensity of these diffraction lines is increasing with increasing temperature. At $779{ }^{\circ} \mathrm{C}$, $\mathrm{CoO}$ becomes the stable phase due to the reduction of $\mathrm{Co}_{3} \mathrm{O}_{4} \cdot{ }^{17,30}$

\section{DISCUSSION}

\subsection{Time-Enhanced Performance due to In Situ}

Reaction. Figure 8 shows an overview of the monotonous increase in $P_{\max }$ of the modules investigated (Figures 2 and 3 ). A reaction layer between the $\mathrm{n}$ - and p-materials is developed during high-temperature testing followed by a significant decrease in thickness from the hot to the cold end (Module1$0 \mathrm{~h}$ ) when $\Delta T$ is applied (sketched in Figure 1). The absence of the reaction layer at medium and low temperatures $(25 \%$ of height $\sim 2.7 \mathrm{~mm})$ corresponds to a significant degree of shortcircuiting $(\sim 40 \%)$ between the $\mathrm{p}$ - and n-legs resulting in low 


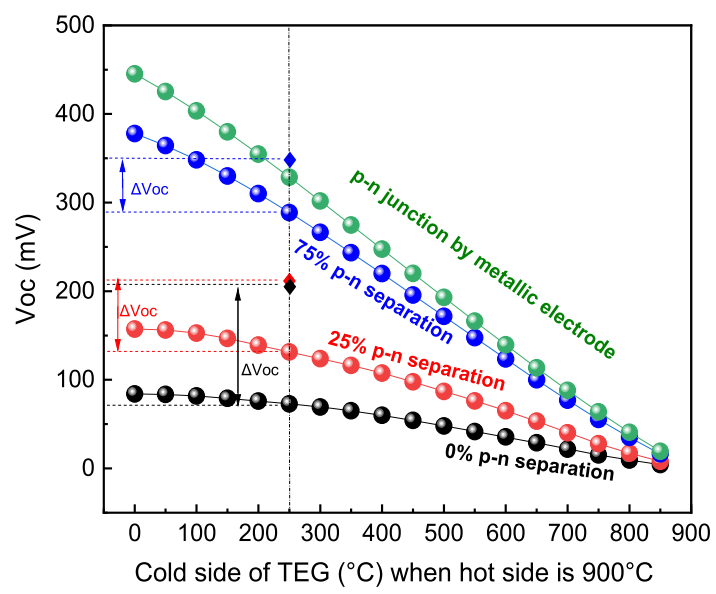

Figure 4. Calculated (COMSOL) open-circuit voltages $\left(V_{\text {oc }}\right)$ as a function of $\Delta T$ for modules with different cell design. A dotted vertical line represents experimental cold side temperature during the module characterization at the $900{ }^{\circ} \mathrm{C}$ hot side. Three $V_{\text {oc }}$ values measured at $900{ }^{\circ} \mathrm{C}$ hot side of Module1-0h (black diamond solid), Module2-25\%LAO (red diamond solid), and Module2-75\%LAO (blue diamond solid) were taken from Table 1 for comparison.

power output. Although Module1-0h shows the lowest performance (Figure 8a), a significant increase in performance is observed with time (Figure $8 \mathrm{~b}$ ) due to the beneficial reactions taking place at the high-temperature end of the device. Inner resistance of the modules $(R)$ decreases as temperature increases due to a combination of reduced resistance with temperature (Figure $6 \mathrm{c}$ ) and consolidation of electrical contact at the high-temperature end of the module with time (sintering). Figure 8a shows a significant difference in $R$ between Module1-24h $(2.5 \Omega)$ and Module2-75\%LAO $(>4 \Omega)$, which is due to the pre-sintering of Module1-24h at $900{ }^{\circ} \mathrm{C}$ for $24 \mathrm{~h}$ prior to testing and establishing an enhanced electrical contact between the legs. The higher resistance observed for Module2-75\%LAO is due to the absence of the pretreatment; this module was tested as received from spark plasma sintering (SPS). However, Figure 8a shows a significant decrease in $R$ with time for Module2-75\%LAO, corresponding to a continuous improvement in the electrical contact between the legs at the high-temperature end of the module. There is no clear trend between $R$ and $V_{\text {oc }}$ (Figures 2, 3, and 8a), and the reason may be because $R$ is measured while a current passes through the module and $V_{\text {oc }}$ is the potential at opencircuit (zero current).

Module1-24h with a uniform thickness of the hybrid $\mathrm{p}-\mathrm{n}$ junction prior to the test, resulted in moderate time-enhanced performance (Figure 8). However, $P_{\max }$ is much higher than that of Module1-0h, even after $42 \mathrm{~h}$ of isothermal testing (Figure 8). These observations support our assumption that the reaction layer can work as an electrical insulating material at moderate and low temperatures, reducing the degree of short-circuiting and enhancing the power output.

An electrical insulator (LAO) was applied in the Module2series (Figure 1), and a time-enhanced performance (Figures $3 \mathrm{~b}, \mathrm{~d}$ and 8 ) was observed. The performance of Module2-25\% LAO is lower than that of Module1-24h, likely due to the absence of a reaction layer along the mid-parts of the interface between the $\mathrm{n}$ - and $\mathrm{p}$-legs, reducing the power due to shortcircuiting. However, extending the electrical insulating layer (LAO) to $75 \%$ of the total length results in a significant enhancement in performance. Module2-75\% shows the highest $P_{\max }$ among all modules tested and shows the effect of separating the legs electrically and suppressing the extent of short-circuiting. Module2-75\% also demonstrates a timeenhanced performance interpreted as an improved electrical contact between the legs with time at the hot end of the device. These observations are supported by the COMSOL modeling presented in Figure 4. The modeling is based on the contact between various parts of the legs, ranging from contact between the legs over the full length ( $0 \%$ separation) to contact only at the high-temperature end of the module (metallic interconnect). The measured $V_{\text {oc }}$ for all modules is enhanced compared to modeled values and confirms the beneficial effect of the phases formed at the interface between the legs.

However, as opposed to Module2-25\% (Figure 3b), $V_{\text {oc }}$ of Module2-75\% decreases with time (Figure 3d). Because the $V_{\text {oc }}$ is proportional to the Seebeck coefficient and temperature gradient, the observed reduction is somewhat surprising and not easily explained. However, it might be a side-effect related to thermal excitation and separation of bipolar charge carriers from the space charge region (by a built-in field), ${ }^{31,32}$ since the thermopower drop could be caused by an increase in charge carrier concentration in both the active components. ${ }^{31}$
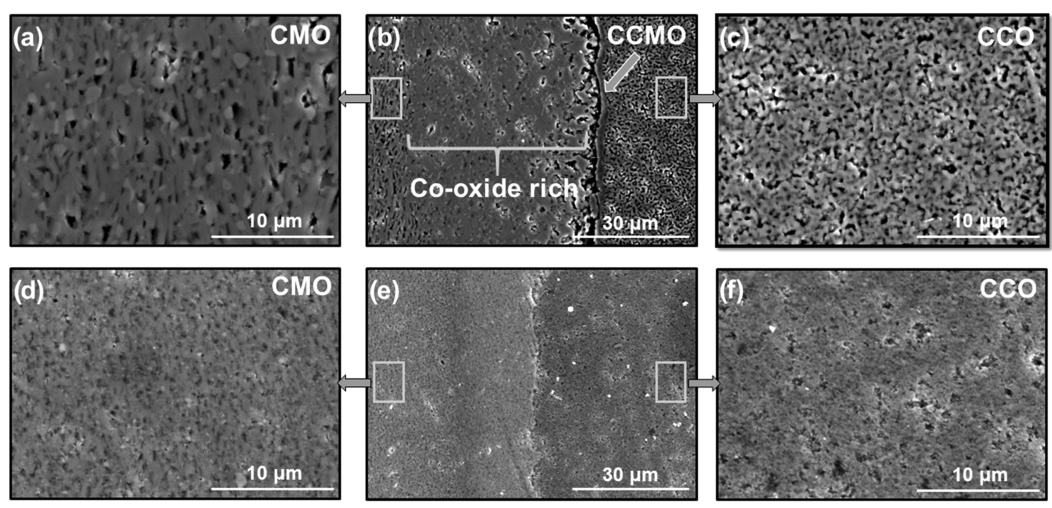

Figure 5. SEM micrographs of cross-sections of Module1-0h after an isothermal hold at $900{ }^{\circ} \mathrm{C}$ hot and $250{ }^{\circ} \mathrm{C}$ cold side temperature for $44 \mathrm{~h}$. Details of the position of the cross-sections: hot side CCO (a), hot side CCO-CMO interface (b), hot side CMO (c), cold side CCO (d), cold side CCO-CMO interface (e), and cold side CMO (f). Thick and thin in situ formed layers in (b) correspond to the Co-oxide rich phase and CCMO layer, respectively. A transition point from unreacted (e) to reacted (b) p-n junction is about $2.7 \mathrm{~mm}$ in height, as illustrated in Figure 1. 

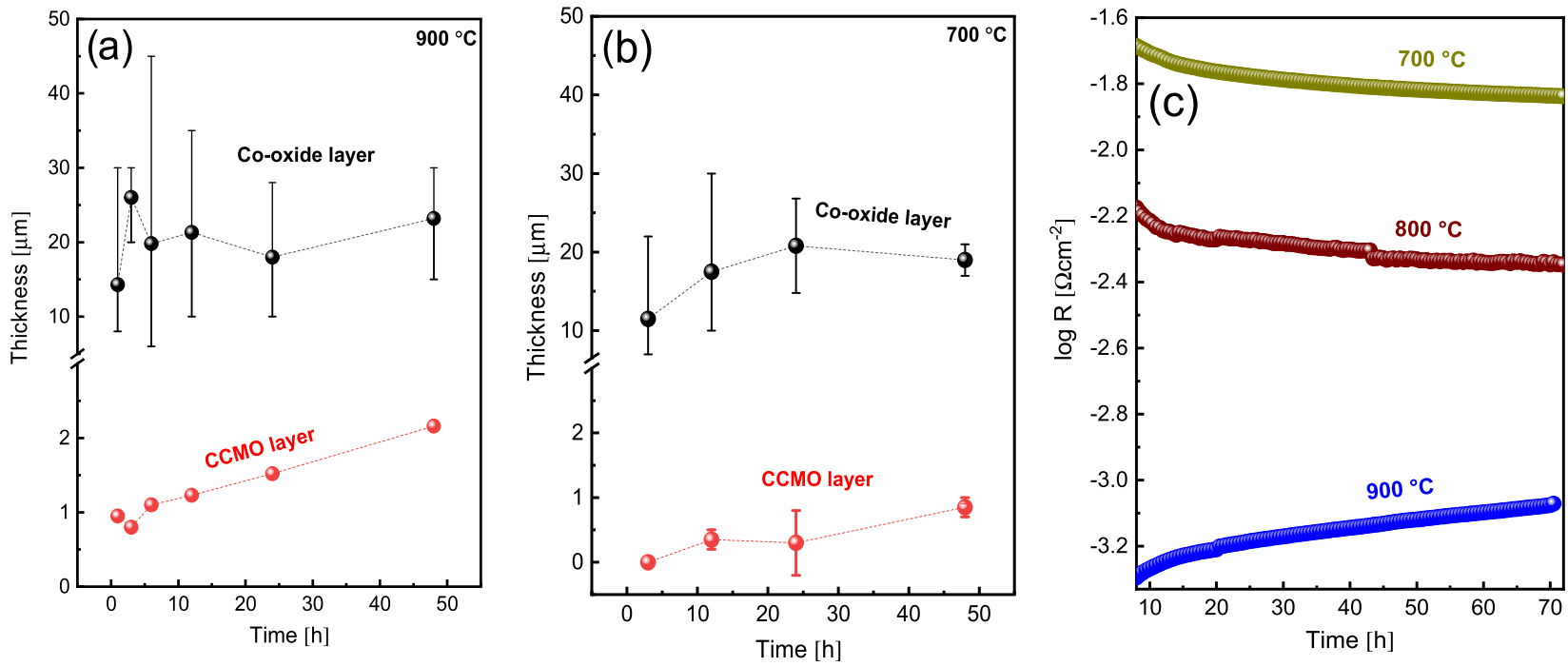

Figure 6. Thicknesses of in situ formed layers (Co-oxide-black symbol and CCMO—red symbol) as a function of annealing time at (a) $900{ }^{\circ} \mathrm{C}$ and (b) $700{ }^{\circ} \mathrm{C}$. Resistance of hybrid $\mathrm{p}-\mathrm{n}$ junctions as a function of time at 700,800 , and $900{ }^{\circ} \mathrm{C}$ is shown in (c).

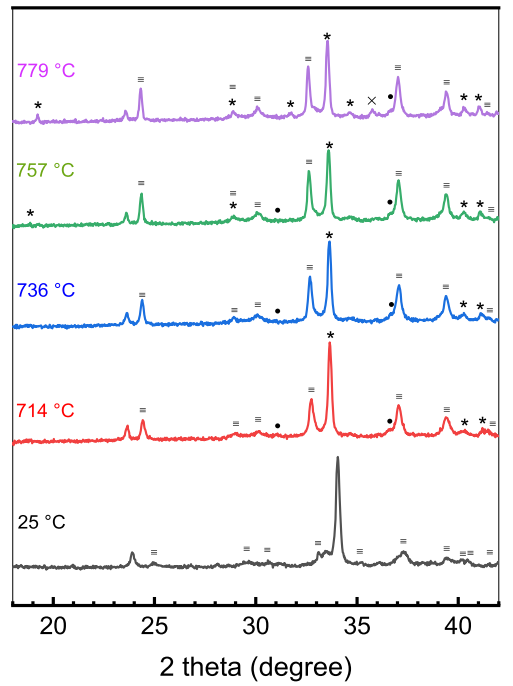

Figure 7. HT-XRD of CCO-CMO powder mixture: $\mathrm{Ca}_{3} \mathrm{Co}_{4-x} \mathrm{O}_{9+\delta}$ $(\equiv), \mathrm{CaMnO}_{3-\delta}(\square), \mathrm{Co}_{3} \mathrm{O}_{4}(\bullet), \mathrm{Ca}_{3} \mathrm{Co}_{2-x} \mathrm{Mn}_{x} \mathrm{O}_{6}(*)$, and $\mathrm{CoO}$ $(\times)$.

Although Module2-75\% shows the benefit of inserting an electrical insulating material (LAO) between the legs, the Module1 series holds great promise for future manufacturing of oxide-based devices based on CMO and CCO. The significant decrease in the resistivity of the reaction layer with temperature (Figure 6) shows that co-sintering of $\mathrm{CMO}$ and $\mathrm{CCO}$ is a promising approach to simplify the production of stable modules, which can operate at high temperatures in air. Our investigation also shows that there are ample opportunities to enhance the performance further by even more accurate control of the variation in thickness of the reaction layer along the interface between $\mathrm{CMO}$ and CCO. This study is also encouraging with respect to high-temperature and long-term operation of the modules. In conclusion, our approach enables "smart engineering" through simple design, easy fabrication, and good performance.

\section{CONCLUSIONS}

The influence of the high-temperature reaction at the $p-n$ junction and the cell design alteration on the performance of CMO-CCO-based modules were analyzed. The interfacial reaction occurs above $700{ }^{\circ} \mathrm{C}$ and results in the formation of a hybrid $\mathrm{p}-\mathrm{n}$ junction (CCO/CCMO/Co-oxide/CMO), demonstrating a time-enhanced performance. Unique electrical properties of the hybrid $\mathrm{p}-\mathrm{n}$ junction were utilized to manufacture a module with a conductive top and nonconductive bottom side, and the reaction layer was an electrical insulating material at moderate and low temperatures. The maximum increase in $P_{\max }$ over 2 days was realized by Module2-25\%LAO, corresponding to a $21 \%$ increase, while the highest $P_{\max }$ of $7.2 \mu \mathrm{W}\left(\sim 29 \mathrm{~mW} / \mathrm{cm}^{2}\right)$ was generated by Module2-75\%LAO. The present work provides a novel platform for designing a range of interface-based modules stable at high temperatures under an ambient atmosphere.

\section{EXPERIMENTAL SECTION}

5.1. Processing. Powders of the p-type $\mathrm{Ca}_{3} \mathrm{Co}_{4-x} \mathrm{O}_{9+\delta}$ (CCO), electrical insulating $\mathrm{LaAlO}_{3}$ (LAO), and n-type $\mathrm{CaMnO}_{3-\delta} / \mathrm{CaMn}_{2} \mathrm{O}_{4}$ composite (CMO) were synthesized by spray pyrolysis (CerPoTech AS, Trondheim, Norway). Two series of modules with different designs were constructed: (i) co-sintered large-area $\mathrm{p}-\mathrm{n}$ junction (Module1) and (ii) cosintered $\mathrm{p}-\mathrm{n}$ junction together with LAO tape placed between the $\mathrm{p}$ - and n-type materials (Module2). LAO tapes were prepared by tape casting followed by lamination and cutting, with the purpose of partially separating the active components in the module. The length of the LAO tapes was such that 25 and $75 \%$ of the height of the module was separated by the LAO layer ( 3.3 and $8.8 \mathrm{~mm}$, respectively); hence the samples were referred to as Module2-25\%LAO and Module2-75\%LAO. Binder removal from tapes is described elsewhere. ${ }^{25}$ The thermoelectric performance of Module1-0h was characterized as received from the spark plasma sintering (SPS, Dr Sinter 825, Saitama, Japan), while Module1-24h was heat-treated at $900{ }^{\circ} \mathrm{C}$ for $24 \mathrm{~h}$ prior to the assessment of the performance. The performance of the Module2 samples was also characterized as received from SPS. The preparation of Module1-0h and Module1-24h was based on filling of the 

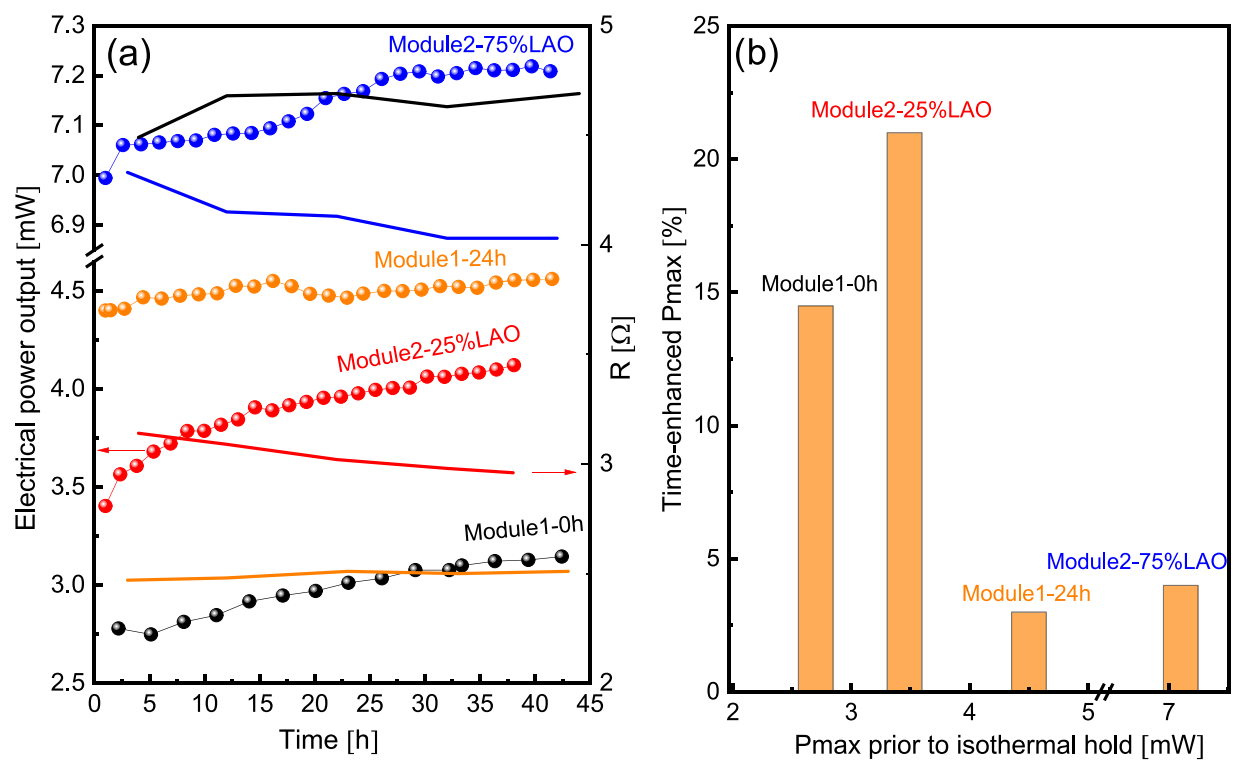

Figure 8. (a) Overview of $P_{\max }$ (spheres) and inner resistance, $R$ (solid lines) of different modules exposed to $900{ }^{\circ} \mathrm{C}$ hot and $250{ }^{\circ} \mathrm{C}$ cold side as a function of time, and (b) a histogram indicates the percentage of time-enhancement during the isothermal test.

graphite dies $(12 \mathrm{~mm})$ with $\mathrm{CMO}$ and $\mathrm{CCO}$ powders according to ref 25. In the case of Module2-25\%LAO and Module2-75\%LAO, an electrically insulating LAO tape was placed on the $\mathrm{CMO}$ powder before $\mathrm{CCO}$ powder was poured into the die. All four modules were fabricated by spark plasma co-sintering in a vacuum at $860{ }^{\circ} \mathrm{C}$ for $3 \mathrm{~min}$ and $75 \mathrm{MPa}$, at $160 \mathrm{~K} / \mathrm{min}$ heating rate. A small area of about $0.6 \mathrm{~mm}$ from the top and the bottom of the co-sintered pellets were removed by grinding/polishing to ensure vertical free-standing modules $(\sim 10.7 \mathrm{~mm}$ height) and low thermal contact resistance. The final thicknesses of CCO and CMO in the modules were $\sim 0.9$ and $3.5 \mathrm{~mm}$, respectively.

The same sintering conditions and geometry as those used for module fabrication were used for the preparation of 13 assintered CCO-CMO junctions, three for in situ isothermal I$V$ measurements, and 10 for SEM/energy-dispersive X-ray spectroscopy (EDS) analysis to understand the growth of the in situ formed layers at different temperatures.

$\mathrm{Ca}_{3} \mathrm{Co}_{4-x} \mathrm{O}_{9+\delta}$ (CCO) and n-type $\mathrm{CaMnO}_{3-\delta} / \mathrm{CaMn}_{2} \mathrm{O}_{4}$ ( $\mathrm{CMO}$ ) powder mixture ( $\mathrm{CCO}-\mathrm{CMO}$ mixture) was prepared by hand mixing in a mortar, followed by mixing in isopropanol using a magnetic stirrer.

5.2. Characterization. The disk-shaped modules with small flat regions at the top and bottom were placed vertically on an alumina plate. $\mathrm{CCO}$ and $\mathrm{CMO}$ were brought in contact with $\mathrm{Pt}$-wires at the cold side using a commercial silver paste. Modules with Pt-wires embedded in silver paste were heated at $280{ }^{\circ} \mathrm{C}$ for $2 \mathrm{~h}$ in ambient air, to obtain sufficient electrical contact between the Pt-wires and the active components. The characterization of the modules was performed in ambient air, via variation of the load resistance at 700,800 , and $900{ }^{\circ} \mathrm{C}$, corresponding to thermal gradients $(\Delta T)$ of 512,606 , and 652 ${ }^{\circ} \mathrm{C}$, respectively. The $\Delta T \mathrm{~s}$ were established by heating the hot side of the module using a Joule heater, while the cold side was cooled using a watercooler. The temperature measurements were carried out using two S-type thermocouples. A voltmeter was connected in parallel to the ampere meter, variable resistor (in series to each other), and to the module. Current-voltage curves were recorded during automatic switching of load resistance, when thermal equilibria were established at each temperature. After the characterization at 700, 800, and 900 ${ }^{\circ} \mathrm{C}$, respectively, all modules were exposed to isothermal tests at $900{ }^{\circ} \mathrm{C}\left(\Delta T \sim 652{ }^{\circ} \mathrm{C}\right)$ where the open-circuit voltage $\left(V_{\mathrm{oc}}\right)$, short-circuit current $\left(I_{\mathrm{sc}}\right)$, and electrical power output $\left(P_{\max }\right)$ were recorded at given times.

After characterization, Module1-0h was polished with a diamond paste (DiaPro NapB1) to $1 \mu \mathrm{m}$ smoothness and coated with carbon (Cressington Carbon Coater 208, Watford, U.K.) for microstructural characterization by SEM (Hitachi S$3400 \mathrm{~N}$, Tokyo, Japan).

Three as-sintered $\mathrm{CCO}-\mathrm{CMO}$ samples with identical geometry as Module1-0h were horizontally placed in a ProboStat cell (NORECS, Oslo, Norway) for isothermal characterization by current-voltage measurements at 700, 800, and $900{ }^{\circ} \mathrm{C}$ for $72 \mathrm{~h}$ using a Gamry Reference 3000 Potentiostat.

In situ high-temperature X-ray diffraction (HT-XRD) measurements on the dried $\mathrm{CCO}-\mathrm{CMO}$ powder mixture were performed up to $779{ }^{\circ} \mathrm{C}$ with steps of $22^{\circ} \mathrm{C}$. The powder mixture was placed into an alumina sample holder mounted into a Bruker D8 Advance diffractometer (Karlsruhe, Germany) with a $\mathrm{Cu} \mathrm{K} \alpha$ source and VÅNTEC Superspeed detector and heated with a radiant heater. The rate of heating was $0.1^{\circ} \mathrm{C} \cdot \mathrm{s}^{-1}$. The temperature was calibrated by refining the lattice parameters of $\mathrm{Al}_{2} \mathrm{O}_{3}$ powder as a function of temperature. The $2 \theta$ range of $10-75^{\circ}$ was scanned with a step size of $0.025^{\circ}$ with $4 \mathrm{~s}$ per step, giving a total collection time of about $3 \mathrm{~h}$ per scan. Each scan was delayed by $30 \mathrm{~min}$ to ensure that the sample had equilibrated at the set temperature.

The fabricated modules were modeled using a finite element framework COMSOL Multiphysics, in which the coupled differential equations describe the electrical current density and the heat flux, as given in refs 33,34 . We modeled a 2D crosssection of the modules where a heat loss to the surroundings was not considered. Material properties for the modeled materials were taken from Kanas et al. ${ }^{25}$ The model was used primarily to calculate the open-circuit voltage $\left(V_{\text {oc }}\right)$ for the various alternative cell designs, as this parameter does not depend on any electrical resistance of the interfaces between electrodes and active components, and could thus directly be 
compared to experimental values. The $V_{\text {oc }}$ was calculated as a function of the temperature gradient within the module with different $\mathrm{p}-\mathrm{n}$ areas.

\section{ASSOCIATED CONTENT}

\section{SI Supporting Information}

The Supporting Information is available free of charge at https://pubs.acs.org/doi/10.1021/acsomega.0c04134.

Details about calculated resistances of the individual pand $\mathrm{n}$-type materials together with the total resistance of the hybrid $\mathrm{p}-\mathrm{n}$ junction developed at 700,800 , and 900 ${ }^{\circ} \mathrm{C}$ (PDF)

\section{AUTHOR INFORMATION}

\section{Corresponding Author}

Nikola Kanas - Department of Materials Science and Engineering, Norwegian University of Science and Technology (NTNU), 7491 Trondheim, Norway; Department of Energy Conversion and Storage, Technical University of Denmark,

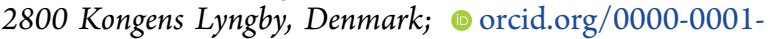
7906-7862; Email: nikola.kanas@ntnu.no

\section{Authors}

Rasmus Bjørk - Department of Energy Conversion and Storage, Technical University of Denmark, 2800 Kongens Lyngby, Denmark

Kristin Høydalsvik Wells - Department of Materials Science and Engineering, Norwegian University of Science and Technology (NTNU), 7491 Trondheim, Norway

Raphael Schuler - Department of Chemistry, University of Oslo, FERMiO, 0349 Oslo, Norway

Mari-Ann Einarsrud - Department of Materials Science and Engineering, Norwegian University of Science and Technology (NTNU), 7491 Trondheim, Norway; orcid.org/00000002-3017-1156

Nini Pryds - Department of Energy Conversion and Storage, Technical University of Denmark, 2800 Kongens Lyngby, Denmark; (1) orcid.org/0000-0002-5718-7924

Kjell Wiik - Department of Materials Science and Engineering, Norwegian University of Science and Technology (NTNU), 7491 Trondheim, Norway

Complete contact information is available at: https://pubs.acs.org/10.1021/acsomega.0c04134

\section{Notes}

The authors declare no competing financial interest.

\section{ACKNOWLEDGMENTS}

Financial support from The Research Council of Norway under the program Nano2021 of the project (Number 228854) "Thermoelectric materials: Nanostructuring for improving the energy efficiency of thermoelectric generators and heat-pumps" (THELMA). Dr. Hao Yin is acknowledged for technical support provided at Technical University of Denmark. N.P. and R.B. would like to thank the support from the European Union's H2020 Programme under Grant Agreement No. 824072-HARVESTORE

\section{REFERENCES}

(1) Kvande, H.; Rye, K.; Stokka, P.; Sørlie, M. In The 17th Course on Fundamentals and their Application in Aluminium Production, Trondheim, Norway, May 28-June 07, 2013.
(2) Xie, W.; Tang, X.; Yan, Y.; Zhang, Q.; Tritt, T. M. High thermoelectric performance BiSbTe alloy with unique low-dimensional structure. J. Appl. Phys. 2009, 105, No. 113713.

(3) Joshi, G.; Lee, H.; Lan, Y.; Wang, X.; Zhu, G.; Wang, D.; Gould, R. W.; Cuff, D. C.; Tang, M. Y.; Dresselhaus, M. S.; Chen, G.; Ren, Z. Enhanced thermoelectric figure-of-merit in nanostructured p-type silicon germanium bulk alloys. Nano Lett. 2008, 8, 4670-4674.

(4) Tsubota, T.; Ohtaki, M.; Eguchi, K.; Arai, H. Thermoelectric properties of $\mathrm{Al}$-doped $\mathrm{ZnO}$ as a promising oxide material for hightemperature thermoelectric conversion. J. Mater. Chem. 1997, 7, 8590.

(5) LeBlanc, S.; Yee, S. K.; Scullin, M. L.; Dames, C.; Goodson, K. E. Material and manufacturing cost considerations for thermoelectrics. Renewable Sustainable Energy Rev. 2014, 32, 313-327.

(6) Jaakkola, K.; Tappura, K. Exploitation of Transparent Conductive Oxides in the Implementation of a Window-Integrated Wireless Sensor Node. IEEE Sens. J. 2018, 18, 7193-7202.

(7) Feng, Y.; Jiang, X.; Ghafari, E.; Kucukgok, B.; Zhang, C.; Ferguson, I.; Lu, N. Metal oxides for thermoelectric power generation and beyond. Adv. Compos. Hybrid Mater. 2018, 1, 114-126.

(8) Bjørk, R. The universal influence of contact resistance on the efficiency of a thermoelectric generator. J. Electron. Mater. 2015, 44, 2869-2876.

(9) Wang, S.; Xie, T.; Xie, H. Experimental study of the effects of the thermal contact resistance on the performance of thermoelectric generator. Appl. Therm. Eng. 2018, 130, 847-853.

(10) He, R.; Schierning, G.; Nielsch, K. Thermoelectric Devices: A Review of Devices, Architectures, and Contact Optimization. Adv. Mater. Technol. 2018, 3, No. 1700256.

(11) Hung, L. T.; Van Nong, N.; Han, L.; Bjørk, R.; Ngan, P. H.; Holgate, T. C.; Balke, B.; Snyder, G. J.; Linderoth, S.; Pryds, N. Segmented thermoelectric oxide-based module for high-temperature waste heat harvesting. Energy Technol. 2015, 3, 1143-1151.

(12) Hung, L. T.; Van Nong, N.; Linderoth, S.; Pryds, N. Segmentation of low-cost high efficiency oxide-based thermoelectric materials. Phys. Status Solidi A 2015, 212, 767-774.

(13) D’Angelo, J.; Case, E. D.; Matchanov, N.; Wu, C-I.; Hogan, T. P.; Barnard, J.; Cauchy, C.; Hendricks, T.; Kanatzidis, M. G. Electrical, thermal, and mechanical characterization of novel segmented-leg thermoelectric modules. J. Electron. Mater. 2011, 40, 2051-2061.

(14) Skomedal, G.; Vehus, T.; Kanas, N.; Singh, S. P.; Einarsrud, M.A.; Wiik, K.; Middleton, P. H. Long term stability testing of oxide unicouple thermoelectric modules. Mater. Today Proc. 2019, 8, 696705 .

(15) Shimoyama, J.; Horu, S.; Otzschi, L.; Sano, M.; Kishio, K. Oxygen nonstoichiometry in layered cobaltite $\mathrm{Ca}_{3} \mathrm{Co}_{4} \mathrm{O}_{\mathrm{y}}$. Jpn. J. Appl. Phys. 2003, 42, L194-L197.

(16) Schrade, M.; Fjeld, H.; Finstad, T. G.; Norby, T. Electronic transport properties of $\left[\mathrm{Ca}_{2} \mathrm{CoO}_{3-\delta}\right]\left[\mathrm{CoO}_{2}\right]$. J. Phys. Chem. C 2014, $118,2908-2918$.

(17) Kanas, N.; Singh, S. P.; Rotan, M.; Saleemi, M.; Bittner, M.; Feldhoff, A.; Norby, T.; Wiik, K.; Grande, T.; Einarsrud, M.-A. Influence of processing on stability, microstructure and thermoelectric properties of $\mathrm{Ca}_{3} \mathrm{Co}_{4-\mathrm{x}} \mathrm{O}_{9+\delta}$. J. Eur. Ceram. Soc. 2018, 38, 1592-1599.

(18) Bocher, L.; Aguierre, M. H.; Logvinovich, D.; Shkabko, A.; Robert, R.; Trottman, M.; Weidenkaff, A. CaMn ${ }_{1-\mathrm{x}} \mathrm{Nb}_{\mathrm{x}} \mathrm{O}_{3}(\mathrm{x} \leq 0.08)$ perovskite-type phases as promising new high-temperature n-type thermoelectric materials. Inorg. Chem. 2008, 47, 8077-8085.

(19) Taguchi, H.; Nagao, M.; Sato, T.; Shimada, M. Hightemperature phase transition of $\mathrm{CaMnO}_{3-\delta}$. J. Solid State Chem. 1989, 78, 312-315.

(20) Singh, S. P.; Kanas, N.; Desissa, T. D.; Einarsrud, M.-A.; Norby, T.; Wiik, K. Thermoelectric properties of non-stoichiometric $\mathrm{CaMnO}_{3-\delta}$ composites formed by redox-activated exsolution. J. Eur. Ceram. Soc. 2020, 40, 1344-1351.

(21) Maignan, A.; Hébert, S.; Martin, C.; Flahaut, D. One dimensional compounds with large thermoelectric power: $\mathrm{Ca}_{3} \mathrm{Co}_{2} \mathrm{O}_{6}$ 
and $\mathrm{Ca}_{3} \mathrm{CoMO}_{6}$ with $\mathrm{M}=\mathrm{Ir}^{4+}$ and $\mathrm{Rh}^{4+}$. Mater. Sci. Eng., B 2003, 104, $121-125$.

(22) Hervoches, C. H.; Okamoto, H.; Kjekshus, A.; Fjellvåg, H.; Hauback, B. C. Crystal structure and magnetic properties of the solidsolution phase $\mathrm{Ca}_{3} \mathrm{Co}_{2-\mathrm{v}} \mathrm{Mn}_{\mathrm{v}} \mathrm{O}_{6}$. J. Solid State Chem. 2009, 182, 331338.

(23) Kanas, N.; Singh, S. P.; Rotan, M.; Desissa, T. D.; Norby, T.; Wiik, K.; Grande, T.; Einarsrud, M.-A. Thermoelectric properties of $\mathrm{Ca}_{3} \mathrm{Co}_{2-x} \mathrm{Mn}_{x} \mathrm{O}_{6}(x=0.05,0.2,0.5,0.75,1)$. Materials 2019, 12, No. 497.

(24) Golovkin, B. V.; Bazuev, G. V. Phase equilibria in the system $\mathrm{CaO}-\mathrm{CoO}-\mathrm{Co}_{2} \mathrm{O}_{3}-\mathrm{MnO}-\mathrm{MnO}_{2}$. Russ. J. Gen. Chem. 2010, 80, 213-218.

(25) Kanas, N.; Bittner, M.; Desissa, T. D.; Singh, S. P.; Norby, T.; Feldhoff, A.; Grande, T.; Wiik, K.; Einarsrud, M.-A. All-oxide thermoelectric module with in situ formed non-rectifying complex $\mathrm{p}-\mathrm{p}-\mathrm{n}$ junction and transverse thermoelectric effect. ACS Omega 2018, 3, 9899-9990.

(26) Gunnæs, A. E.; Tofan, R.; Berland, K.; Gorantla, S.; Storaas, T.; Desissa, T. D.; Schrade, M.; Persson, C.; Einarsrud, M.-A.; Wiik, K.; Norby, T.; Kanas, N. Chemical stability of $\mathrm{Ca}_{3} \mathrm{Co}_{4-\mathrm{x}} \mathrm{O}_{9+\delta} / \mathrm{CaMnO}_{3-\delta}$ $\mathrm{p}-\mathrm{n}$ junction for oxide based thermoelectric generators. RSC Adv. 2020, 10, 5026-5031.

(27) Seetawan, T.; Singsoog, K.; Srichai, S.; Thanachayanont, C.; Amornkitbamrung, V.; Chindaprasirt, P. Thermoelctric energy conversion of $p-\mathrm{Ca}_{3} \mathrm{Co}_{4} \mathrm{O}_{9} / n-\mathrm{CaMnO}_{3}$ module. Energy Procedia 2014, 61, 1067-1070.

(28) Phaga, P.; Vora-Ud, A.; Seetawan, T. Invention of low cost thermoelectric generators. Procedia Eng. 2012, 32, 1050-1053.

(29) Urata, S.; Funahashi, R.; Mihara, T. In Power Generation of a pType $\mathrm{Ca}_{3} \mathrm{Co}_{4} \mathrm{O}_{9} / n$-Type $\mathrm{CaMnO}_{3}$ Module. Proceedings of the International Conference on Thermoelectrics, Vienna, Austria, 6-10 August, 2006; p 501.

(30) Kang, M.-G.; Cho, K.-H.; Kim, J.-S.; Nahm, S.; Yoon, S.-J.; Kang, C.-Y. Post-calcination, a novel method to synthesize cobalt oxide-based thermoelectric materials. Acta Mater. 2014, 73, 251-258.

(31) Maculewicz, F.; Wagner, T.; Arzi, K.; Hartmann, N.; Weimann, N.; Schmechel, R. Experimental evidence for the separation of thermally excited bipolar charge carries within a p-n junction: A new approach to thermoelectric materials and generators. J. Appl. Phys. 2019, 125, No. 184502.

(32) Span, G.; Wagner, M.; Grasser, T.; Holmgren, L. Miniaturized TEG with thermal generation of free carriers. Phys. Status Solidi RRL 2007, 1, 241-243.

(33) Bjørk, R.; Christensen, D. V.; Eriksen, D.; Pryds, N. Analysis of the internal heat losses in a thermoelectric generator. Int. J. Therm. Sci. 2014, 85, 12-20.

(34) Chen, L.; Li, J.; Sun, F.; Wu, C. Performance optimization of a two-stage semiconductor thermoelectric-generator. Appl. Energy 2005, $82,300-312$. 